\title{
Millennial Students' Mental Models of Search: Implications for Academic Librarians and Database Developers
}

\author{
Lucy Holman \\ Langsdale Library \\ University of Baltimore \\ 1420 Maryland Avenue \\ Baltimore, MD 21218 \\ lholman@ubalt.edu \\ 410.837.4333 \\ 410.837-4319 (fax)
}




\section{Millennial Students' Mental Models of Search: Implications for Academic Librarians and Database Developers}

\section{$\underline{\text { Abstract }}$}

Today's students exhibit generational differences in the way they search for information. Observations of first-year students revealed a proclivity for simple keyword or phrases searches with frequent misspellings and incorrect logic. Although no students had strong mental models of search mechanisms, those with stronger models did construct more complex searches.

\section{Introduction}

As today's college students turn to Google and other public search engines for academic research, libraries and commercial databases face the challenge of meeting students' research needs with new interfaces, algorithms, and methods of instruction. Since the onset of online searching, university librarians have advocated databases that employ controlled vocabulary and require prescribed syntax. However, students entering college today have grown up with simpler interfaces and more natural language searching. With these changes in users' experiences comes a tension between developing technologies designed to capitalize on well-defined metadata and those developed to provide a simple search interface with robust algorithms for spelling variants and synonym rings. Database developers and librarians stand at an important crossroads.

Should students have to learn to use more complex search strategies or should designers develop interfaces that more closely relate to millennials' conceptualization of information retrieval with algorithms that more accurately parse a simpler, more natural language query? If developers choose to do the latter, what search behaviors should inform those design decisions? How does this generation of students differ from their predecessors? What are their mental models of search and how can developers of commercial databases design interfaces and algorithms and librarians design information literacy instruction with an understanding of these mental models. This study examines first-year college students' information-seeking behaviors and identifies 
connections between their mental models of information retrieval and their ability to effectively search for and find scholarly materials.

\section{$\underline{\text { Literature Review }}$}

Societal changes are seen in every generation. Some of these shifts are cyclical; one generation returns to the values of preceding ones. Other shifts, however, reflect changes in technology and innovation and are unique to the latest generation. This generation of collegeage students has come of age in a period of great technological change and upheaval in information sources that have significant impacts on communication, learning and academic research.

Millennial students have grown up in the Information Age. They live in homes with computers and Internet access; they own MP3 players, cell phones and other mobile devices ${ }^{1,2}$. They have been exposed to online sources throughout their lives. As of 2002, $86 \%$ of college students used the Internet; almost half of them began using it in high school or earlier ${ }^{3}$. Today, college students spend an average of almost 20 hours a week on the Internet; $7.4 \%$ are online 40 hours a week ${ }^{4}$. Students are constantly wired and continually connected.

Impacted by their exposure to new technology and communication tools, millennials exhibit generational learning characteristics that impact their approach to information retrieval. Having grown up with online information sources, they do not discriminate between websites and more traditional print and broadcast media. They do not necessarily value peer-reviewed or professionally-edited material online and thus may not start their research with refereed material $^{5}$.

Today's students also demonstrate different cognitive skills than their predecessors. They seem to be "hypertext" learners; their brains have trained to retrieve bits of information 
from multiple sources rather than from a single narrative ${ }^{6}$. Younger students tend to scan sites quickly and click links often. Boys, in particular, rarely read pages in a linear fashion ${ }^{7}$. Some have found that many millennials do not fully read online documents; rather, they scan materials to find small pieces of information within the text ${ }^{8}$. The University College of London (UCL) CIBER Project describes this as "horizontal information seeking;" students often skim material, with as many as $60 \%$ viewing just a few pages of an e-journal article and then "bouncing" to another ${ }^{9}$. This horizontal seeking does not always involve a systematic approach to searching for information; rather, students almost accidentally come across information and use what they immediately find, regardless of relevance ${ }^{10}$.

Millennial students have been dubbed the "Google Generation"11; they have grown up with search engines and although may not retrieve the "best" materials on the web, they may find resources "good enough" to satisfy them. They value ease and convenience over quality" Finding millions of sources through search engines, they may not feel they need more specialized library resources, and they may shy away from those tools that require more skill and expertise to use. They rarely use the advanced features in the search engines, expecting the engine itself to know what they need ${ }^{13}$. Research from the Pew Internet and American Life project $^{14}$ found that $73 \%$ of college students use the Internet more than college libraries for academic research, while only $9 \%$ use the library more than the Internet. A similar Pew study found that the trend continues with younger teenagers, with $94 \%$ using the Internet for assignments, and $71 \%$ viewing the Internet as their primary source of research material ${ }^{15}$.

These statistics obviously concern academic librarians, as many studies indicate that students find search engines easier to use than library databases and view them as effective enough for their information needs. For example, a 2006 study found that $96 \%$ of the college 
students surveyed find Google a valuable source for information, while $84 \%$ found the library website worthwhile. Students rated search engines higher than libraries in terms of ease, convenience, speed and reliability; they ranked library resources higher in accuracy and credibility ${ }^{16}$. It would appear, however, that students value the first four qualities more than the latter two. Most students (55\%) cite difficulty finding the full text of articles and suggest that libraries make their resources easier to access and use. Students say they have difficulty navigating and searching library products ${ }^{17}$. They are frustrated when they find a citation to a relevant source and realize that they can't access the full text of the article ${ }^{18}$. Students prefer searching the Internet to library resources because they often are confused about which databases to use, and they were unaware of or unsuccessful at cross searching in the databases ${ }^{19}$. Students appreciate the simplicity of a single interface to search a variety of sources ${ }^{20}$.

Millennial students may lack the sophistication to understand exactly what information they need and have difficulty developing effective search strategies and judging the relevance or appropriateness of their search results. It is incumbent upon librarians and database vendors to model instruction and design search tools to make them more effective and discriminating.

\section{Mental Models}

A mental model is an internal cognitive representation of a tool or system that helps one master it $^{21}$. It is the user's mental image of a system and its capabilities that he employs to understand how to operate it. This conceptualization of search systems has a profound impact on one's effectiveness with research tools. Researchers have examined the effect of mental models on individuals' use of search systems and user competence since the onset of electronic retrieval. Alexandra Dimitroff found that college students with more robust mental models are more effective searchers in an online library catalog; those without some mental image of the 
system are not as competent ${ }^{22}$. Stephen Kerr discovered that faster searchers have more developed conceptualizations of the system than do slower searchers ${ }^{23}$. Although some research ${ }^{24}$ indicates that users may adapt models as they explore new tools, others find that work in similar systems actually may complicate learning and confuse users. For example, Scharlotte Saxon discovered that middle-school students mistakenly assume that different systems work more similarly than they actually do; students experienced problems in transferring their models from one system to another ${ }^{25}$.

Researchers also have found correlations between effectiveness and age-related differences in mental models of search. Some suggest that individuals with mental models of information retrieval as an online catalog only may have difficulty forming an accurate mental model of Internet searching and may not easily adapt from one system to the other ${ }^{26}$. Some researchers argue that providing conceptual knowledge about a tool or system is not enough to form a new mental mode ${ }^{27}$. Historically, librarians have tried to connect students' existing mental models (for example, use of a telephone directory) to that of an online index ${ }^{28}$. However, as young students may have few, if any, conceptualizations of print references or hierarchical taxonomies and structures, librarians no longer may be able to use such connections in adapting existing mental models.

Several researchers have compared mental models of different user groups. One such study examined the effect of computer experience and education on mental models and found significant differences between students and librarians ${ }^{29}$. For example, librarians see initial search queries as untargeted (more as a shortcut to find relevant subject headings in order to craft more focused searches), whereas students see them as targeted ${ }^{30}$. 
Therefore research on searchers' mental models, particularly those examining age-related differences, may have profound implications for database designers as they develop new interfaces for their discovery tools that retrieve results data from a variety of sources and formats and librarians as they offer explanations of the functions of search tools.

\section{Methodology}

This study used a combination of contextual inquiry and concept mapping methodologies to examine millennial students' mental models and their approach to research. The researcher recruited first-year students from the University of Baltimore (UB) in fall 2008. Although small in number, the 21 participants demographically represented the entering class at UB: $52 \%$ women and 48\% men; 48\% white, $43 \%$ African American and 9\% Asian; with ages ranging from 16 to 19 . All participants had at least one computer at home; $57 \%$ had two or more. Ninety-one percent had a profile on a social networking site. Almost all (95\%) spent at least one hour per day on the internet; $62 \%$ spent more than two hours daily. More than two thirds $(71 \%)$ spent at least one hour surfing the web.

Each student had a research assignment for which he/she chose to use online resources. During a three-week period in September and October 2008, the researcher met with each student for approximately an hour in a university usability lab. The researcher observed students use their natural choice of search engines or article databases as they researched course assignments, videotaping each session and capturing student searches using Morae software. She encouraged each participant to walk her through his/her research process, thinking aloud about his/her search strategies and anticipated search results.

After the researcher observed the student, she concluded each session with an interview consisting of ten questions. The interview included a review of the key words the student used in 
the session, his/her reflections on the success of his/her searches, and possible alternative search terms. There were also several questions designed to ascertain the student's conceptualization of how the search tools used students' terms to generate a list of results. The researcher also asked each participant to draw or diagram the relationship among the terms used and their relationship to items retrieved in the search.

\section{$\underline{\text { Results }}$}

The participants performed 210 discrete searches in 21 distinct search tools; 130 were in search engines, and 80 were in library databases (see Table 1). Sixteen students (76\%) started with a web search engine; three (14\%) began their research with online databases, and two (10\%) started with online encyclopedias (Wikipedia and Encarta). An overwhelming majority of search engine queries $(72 \%)$ were in Google. This mirrors a large international report ${ }^{27}$ where $^{2}$ $68 \%$ of the 396 college students surveyed used Google as their search engine of choice. A large majority of the database searches (almost 74\%) were in Academic Search Premier. In addition to queries in search engines and databases, eight students (5\%) conducted another 14 searches in 11 individual sites, bringing the number of total searches to 224 .

Using a categorization scheme similar to that of Guinee, Eagleton and Hall ${ }^{31}$, searches were characterized into four types: 1) simple, single-term searches, which consisted of a personal name or a one- to three-word concept such as Republican party or three strikes law; 2) topic plus focus searches, which consisted of a string of words containing two related concepts such as Libertarian economic policy or a single Boolean AND search such as democrats and environment, 3) phrase searches, which consisted of a multiple-word descriptive phrase or sentence such as Libertarian policy on pollution, and 4) advanced searches, which employed 
multiple Boolean operators such as political parties and education or schools and 2008 election or (Libertarian or democratic)+(economic or fiscal)+(policy or theory or belief).

Generally students either conducted very simple searches (34\%), using personal names or short phrases that conveyed a single concept or performed topic plus focus searches (30\%) using a single Boolean AND (see Table 2). Students attempted 31 more complex Boolean searches (13.8\%), combining two or more distinct concepts; however, for a majority (22) of those searches, students crafted the queries with inappropriate Boolean operators, particularly in the databases. Students who employed both search engines and databases generally used the same keywords and syntax in both types of search tools.

Approximately $17 \%$ of the queries employed phrases; again, phrase searching was similar in the search engines and databases. Students did not radically change their syntax from search engine to database other than to use the Boolean operators provided in the databases. Three of the phrases were in the form of a question such as does the three strikes law deter crime? The remaining 36 phrases were strings of words such as financial corruption leading to current economic downturn.

In both phrase and topic with focus searches, students used various punctuation including quotation marks, slash marks, parentheses and plus signs, as seen in "poverty and taxes", democratic views on Afghanistan/Iraq, and energy independence + party for socialism and liberation. Frequently, the punctuation did not have the intended effect of focusing results; incorrect punctuation, particularly in the databases, led to searches with limited or no results. Students generally assumed that few results indicated a problem with their choice terms rather than incorrect punctuation or syntax, so they continued to experiment with new search terms rather than review and correct syntax. Several participants, although they did not use such 
punctuation, talked about using parentheses or quotations around phrases. None seemed to recognize difference in phrase search capabilities between search engines and databases.

Six students used Boolean logic (other than a single AND) in 31 searches. Of those six, two used only AND operators. The remaining four used both AND and OR; only two used them correctly, and only one with successful results (one of them misspelled words resulting in unsuccessful searches). These mistakes, paired with frequent misspellings, led to few relevant results in the databases. As they did in cases of incorrect punctuation, students failed to recognize that the lack of results were from logic errors rather than their choice of terms. Misspellings also had a significant impact on students' success and highlighted a major distinction between search engines and database algorithms. Eleven students (52\%) made at least one spelling error. Students rarely noticed these mistakes; only in two instances did the participants catch a misspelling. Google provided a "Did you mean?" set of results, and students clicked the suggested search immediately, appearing to be very familiar with the alternative spelling link. When misspellings led to few or no results in the databases, students assumed there were no articles on the subject rather than question the search input.

Students seemed somewhat haphazard in their strategy to focus their searches or to expand or narrow their set of results. A majority of students (57\%) narrowed a search by adding terms, but few (11\%) consistently used this strategy; others returned to an original overly broad search in a different tool. Only four students seemed deliberate in attempts to focus their searches, but they, too, often did so incorrectly. For the few students who correctly applied limits to their searches, many more students made mistakes in spelling, punctuation or logic, as shown in Table 3. 
Three students performed subject searches in databases; however each of them structured the search inappropriately. For example, one used the phrase 3 strikes law deters crime as the subject rather than just three strikes law; two included Boolean strings like banking and regulat* and United and states in a subject field. The students' use of phrases or Boolean operators sabotaged the effectiveness of subject searching. However, none recognized this, nor did they retry the subject search; they simply modified their keywords or changed the query altogether.

Students could not easily articulate their understanding of why a search may have failed or why they retrieved the results they did. Some comments included, “I don't know how I typed in global warming and got the entire website," and "I don't know exactly why they do it, but ...if you're looking for education and virtues and then you switch to virtues and education for some reason it brings up completely different websites." One noted, "I just took one word out and got a whole other page of information." Still another admitted that she didn't get results "because I was a little too vague," but she could not articulate what specifically was "too vague" about her search terms.

A few students did seem to have a limited notion of adding terms to narrow a search and reducing terms to broaden. One stated, "I think when I take out other words, it makes it a little bit broader, that way more stuff can come up." Another noted, "If I type a synonym I may get more results." However, participants' errors in the use of Boolean operators often negated their use of synonyms or alternative terms.

\section{Mental models}

After observing the students search for materials, the researcher asked several questions to determine students' mental models of search systems. When asked to explain how a search 
engine worked and how it employed search terms, most participants had only a vague sense of keyword matching and the mechanics of website collection. A number of students stated that search terms should be specific, but few could articulate what they meant by specific; only one indicated that a search could be narrowed by adding additional keywords. Several participants said that a search engine determines its results based on what one types in the search box, but they seemed to understand that in terms of keyword as concept rather than as a literal string of letters. For example, one student said, “Google doesn't know exactly what I'm looking for, but I think based on what I search for, they seem to give an idea of what the public usually is looking for in that topic range." One student used an example of narrowing in a hierarchy; he suggested that the word $\operatorname{dog}$ would result in more hits than the breed Shih Tzu. Still, he did not articulate how the search engine read Shih Tzu differently from $d o g$; he seemed to indicate that it was because dog was a broader category than a specific breed. Students also varied in their answers about phrase searching; some believed that the search engine searched for each word used, while others believed that the engines only used the primary terms. One participant stated that the search engine "takes the most basic words from my search and tries to bring up as many searches as it can." He continued by saying," I don't know what it does because I've never thought of this; I just type my words in. Another said, "None of [the search engines] connect all the words together....they just kind of pull out whatever they feel is the most important word."

A few students seemed to recognize that they could narrow a search by adding terms; one stated, for example, that she had recently searched for "pig wearing lipstick Obama speech" to find a video of a recent campaign speech. Others, when asked how to narrow a search, mentioned using techniques such as quotes or advanced searches. Interestingly, no student accurately used quotes in any of the observed searches. Others incorrectly thought that using 
parentheses directed the search engine to search for words as a phrase. Again, these comments confirm studies ${ }^{32}$ that find students don't recognize problems with specific search syntax, logic or spelling.

The researcher also asked students how they would explain a search engine to someone without any knowledge of computers or to give a non-computer analogy in order to elicit their mental models. Few students seemed to have a clear visualization of how a search engine processes a query; 13 students (61\%) presented analogies to print resources, but all of them described them more as storage spaces and did not indicate how such tools would pull out data from a source. Only one participant mentioned anything about classification systems or organizational structures that are relevant to information retrieval. The comparisons all related to what sites held rather than how they or search tools organized data.

In addition to the questions designed to elicit mental models, the researcher asked participants to draw or diagram the relationships between the keywords they used and the results retrieved. An earlier study of students' mental models of the Internet as a whole identified four basic categories of drawings: 1) technical view, 2) functional view, 3) process view and 4) connection view ${ }^{33}$. Here, the mental models were narrower in scope; students drew representations of relationships between keywords and their results. From the 21 drawings, three primary categories emerged:

1) process view. Participants drew images of the entire search process as a task flow diagram, including the search strategies and resulting sources. Figure 1 depicts an example of this category.

2) hierarchical view. Students outlined a broad subject with subtopics or results highlighting aspects of the subject. Figure 2 depicts an example of this category. 
3) network view. Participants in this category diagrammed models of interconnected terms. Figure 3 depicts an example of this view.

In addition to these three views, two students simply listed all the terms they had used in the search in a chart-like form and are not included in these findings.

Few of the diagrams indicated a well-developed mental model of the relationship between search terms and results. For example, few illustrated what terms would focus or expand a search or differences between synonyms and terms relaying multiple concepts. Students showed connections between multiple words but did not demonstrate the nature of those connections or their strength or intensity.

Those participants with a network view performed most of the searches (58.7\%), compared to students with a process $(11.6 \%)$ or hierarchical view (29.6\%). They also constructed the most sophisticated queries; for example, they crafted $83 \%$ of the Boolean searches. Students with a hierarchical model constructed the other 17\%; those with a process model did not use Boolean logic at all (See Table 4). On the other hand, $46 \%$ of the process view searches were simple searches; 79\% were either simple or phrase searches (See Table 5). Among participants with network views, only $25 \%$ were simple searches while $65 \%$ were either Boolean or topic + focus queries.

Although the differences between the three mental models are small, those with a process view seem to demonstrate the least formed mental model and experience the search engine as a "black box" that gives searchers results. They have little understanding of how results are selected and no comprehension of algorithms and therefore build the simplest queries. Conversely, participants with a network view focus more on the query terms themselves. 


\section{$\underline{\text { Discussion }}$}

Although somewhat small in sample size, this study supports several previous studies of students' search skills and sheds light on the connections between students' mental models and their search efficacy. While students stated that search engines retrieve sites by matching keywords, most did not demonstrate a strong conceptual model of search such that they could effectively focus a search to retrieve relevant materials. Furthermore, they were often unable to recognize a problem (incorrect Boolean logic, spelling errors, etc) and resolve it for better results. Most of the students' searching skills were rudimentary at best, and their ability to troubleshoot problems in search syntax was extremely limited. Although those with stronger mental models were able to use more complex strategies, few succeeded in these searches.

When asked about their effectiveness in locating information online, most of the students considered themselves successful that day and believed themselves to be competent searchers overall. They seemed satisfied with using very simple search strings; if they retrieved at least ten items they believed that they had enough material. None expressed concern with the millions of results they retrieved from search engines; only a few reviewed more than the first two pages of results. Although several had some understanding of Boolean logic, few chose to use it and gave up quickly if it did not provide the expected results. Most students preferred simple searches even if they retrieved larger lists of results.

If students are indeed satisfied with simpler searches without the use of advanced techniques, librarians must reconsider training students to use advanced features or Boolean logic if students purposefully choose not to use them or fail to use them correctly. Rather than teaching students more effective search syntax, more attention should be placed on developing critical thinking and evaluative skills. 
The large number of spelling errors and students' failure to notice mistakes calls attention to the difference between search engines and databases in their ability to offer alternative spellings for misspelled words. All of the students who made mistakes in Google seemed very familiar with the "Did you mean?" feature and quickly clicked on the revised search. Database developers who design algorithms that make allowances for spelling errors will facilitate student search success. It is unclear if these errors result from poor spelling skills or just mistakes made in typing haste; however the cause here is irrelevant. Searchers will continue to make spelling or typographical mistakes, and search tools must make accommodations for those mistakes. Some database producers have recently released new products with more robust search mechanisms and others have such products in development, but this is still an area that deserves more attention by vendors.

Although most participants knew that the search engines and databases matched their indexes for keywords used in a search, they did not apply that understanding to specific searches, and they were often ill-equipped to troubleshoot particular problems. In some cases students returned to the same search terms repeatedly with the same results. Some seemed to see the keywords more as concepts rather than as strings of letters to be matched; they would perhaps broaden the concept without broadening their search strategy. For example, they did not consider that sites might only include one political party's stance and therefore unduly limited their results by building queries that required two or more parties in a single site. Furthermore, their choice of synonyms, sometimes automatically generated by Microsoft Word or an online thesaurus, were often off the mark.

Students' lack of robust mental models had a profound effect on the precision of their searches. Unfortunately, most participants considered themselves successful and did not 
recognize this lack of precision. While they have grown up with Internet and search engines, their understanding is superficial at best. Although their skills are rudimentary, they are satisfied with their proficiency and the results they retrieve.

The students' rapid pace of searching, scanning and evaluation is worth notice; it may have led to many of their mistakes and repeating of failed searches. The participants rarely took the time to look at materials for relevance or stopped to consider an appropriate keyword for a search; rather, they tried a search and quickly modified it, only to return to the original search minutes later. This behavior and speed of processing seems consistent with observations of researchers ${ }^{34,35,36}$ who note that millennials tend to move quickly from one bit of information to the next. This rapid pace may result ill-considered queries, and students' impatience may lead to a hasty review of results.

Although this research focused on students' search behaviors, these observations uncovered several other areas for further research. One such area is the way in which students read and process information. At least 18 students quickly skimmed or scan materials searching for keywords. Much like the tools they were using, they seemed to assume relevancy by the frequency of their keywords. Conversely, only seven (33\%) read sites or articles in depth. The notions of hypertext reading and multitasking may significantly impact students' evaluation of the sites and articles they find. This calls for more research in the exploration of millennials' critical thinking skills, the methods they employ and knowledge they apply in evaluating Internet sites and articles for their academic work. Most of the students reviewed retrieved sites and articles very quickly and made decisions to keep sites within seconds. Two thirds of the students made some comment about the quality of the sites they encountered; half of those rated sites favorably based solely on design and layout; others accepted .edu sites as valuable even if they 
had no relevance to the topic. In other cases students made evaluations based on misinformation or lack of knowledge. One student, finding an article from USA Today wondered if the source was a newspaper. Another who found an article from the Baltimore Sun questioned its authenticity despite the full citation and the Sun's URL. One student researching alternative energy sources located Chevron's website. He stated that he did not know who/what Chevron was, but after reviewing the site, thought that the company's information on energy and the environment might provide all he needed for background on the issue. While some students appreciated and trusted sites such as CNN, and the Economist, others disregarded those very sites. One student dismissed a report issued by the Cato Institute because the Institute's home page did not seem informative based on its appearance.

Librarians teaching the three-credit information literacy course at the University of Baltimore recognized many of these behaviors and mental models in their own students; they subsequently modified their lesson plans on search strategies and evaluation as a result of these findings. Instructors now observe students' natural search strategies and assist them in identifying important differences between search engine and database queries in order to have better database results. Instructors have also considered the findings related to students' perceptions of website relevance and credibility and are discussing the use of online editions of print news sources and the implications of evaluations based on design rather than content.

\section{$\underline{\text { Conclusion }}$}

As colleges and universities enroll younger users with more experience with publiclyavailable Internet resources, librarians will continue to see generational shifts in the information retrieval practices and students' search skills and preferences for search tools. Academic librarians who teach information literacy will face the need to reexamine how college students 
today search for and retrieve information and rethink the way they teach younger students search strategies and resource evaluation. Furthermore, librarians who purchase proprietary databases and the producers who design them also must consider younger students' conceptualizations of search and their preferred search methods and strategies. One of the original questions this research posed is whether students (and young faculty) should learn to use complex interfaces with less intuitive search strategies based on mental models of print-based research tools or should designers develop interfaces that more closely relate to millennials' own mental models of Internet-based information retrieval with engines that more accurately and effectively parse a simpler, more natural language query. Some educators believe that to do so would "dumb down" information literacy instruction. However, if today's students do not operate in a linear fashion and learn (and search) by discovery, should then the focus of database development and information literacy instruction be on more effective strategies for refining a search rather than on initially constructing a near-perfect search? Should not more attention be placed on evaluation and critical thinking skills that will endure beyond the specific techniques and syntax necessary for the current search tools?

Although students may not have robust mental models of search tools and may be not be strong searchers, neither will they be likely to want or appreciate instruction that simply teaches advanced search techniques. Students believe themselves to be effective and are satisfied with the results they retrieve. Generally they use whatever information they find if it is relevant and reasonably reliable (and some students may be satisfied without the reliability). Rarely do they refine a search string and continue the search for better sources. In this study all 21 students, regardless of the quality of materials located, were satisfied and did not plan to look for additional material unless they found to be missing certain information. Few had performed truly 
well-crafted searches, but they had found enough for their purposes. Librarians may be forced to accept that users will conduct less-than-perfect searches; many already shift their focus from search to evaluation. This study points to a critical need to address students' evaluation skills.

Database designers also need to consider changes in students' conceptualizations of search and their information retrieval habits. Some leading producers are already incorporating synonym rings and spelling variants in their search algorithms, offering students results when they misspell common terms or use related terms. Still, these engines are not as robust as Google or other search engines. Although they may still allow for complex Boolean or other advanced search syntax, databases may need to redesign interfaces and algorithms to appeal to younger users' preference for simplistic interfaces and natural language searches. Furthermore, as information professionals build data harvesting and discovery tools designed to retrieve items from a variety of sources, the need for more robust algorithms becomes even greater. This has not seemed to be an immediate priority to information professionals; while producers are developing new algorithms the library community does not seem to be demanding more robust tools. Producers who are not developing such algorithms risk losing younger users who believe their searches have failed in their systems without understanding why.

Because students do not seem to have solid or strong mental models of the search mechanisms and thus do not craft well-honed queries database producers should continue to build more robust discovery tools designed to harvest materials in a variety of formats from a variety of sources based on less refined searches. The leading producers must adopt and adhere to metadata standards that will facilitate cross-platform searching. Students and young faculty demand more seamless searches in a single interface regardless of the location or format of the 
material. They expect the system to correct spelling or grammar errors and want to use more natural language in their queries.

Librarians may still continue to strengthen students' conceptualizations of search tools but in a way that appeals to millennials' sense of discovery. If today's students prefer to craft simple queries perhaps information literacy instruction should emphasize problem-solving strategies when searches prove ineffective and concentrate on ways in which students can broaden or narrow results. 


\section{References}

1. Gail Salaway, Judith Borreson Caruso, and Mark Nelson, The ECAR Study of Undergraduate Students and Information Technology, 2008 (Research Study, Vol. 8). Boulder, CO:

EDUCAUSE Center for Applied Research (2008), 43-44. Available:

http://www.educause.edu/ecar.

2. Amanda Lenhart, Mary Madden, and Paul Hitlin, Teens and Technology: Youth Are Leading the Transition to a Fully Wired and Mobile Nation. Washington, DC: Pew Internet and American Life Project, (July 27, 2005), 9-10. Available: http://www.pewinternet.org/ /media/Files/Reports/2005/PIP_Teens_Tech_July2005web.pdf.pdf

3. Steve Jones, The Internet Goes to College: How Students Are Living in the Future with Today's Technology. Washington, DC: Pew Internet and American Life Project, (September 15, 2002), 6. Available: http://www.pewinternet.org/ /media//Files/Reports/2002/PIP_College_Report.pdf.pdf

4. Salaway, Caruso and Nelson, ECAR Study of Undergraduate Students, 44.

5. Stephen Abram and Judy Luther, "Born with the Chip," Library Journal, 129, no. 8 (May 1, 2004), 34.

6. Marc Prensky, "Digital Natives, Digital Immigrants, part II: Do they really think differently?" On the Horizon, 9 (6), (2001), 3-4. Available:

http://www.marcprensky.com/writing/

7. University College London (UCL) CIBER Project, Information Behaviour of the Researcher of the Future: A CIBER briefing paper (January 11, 2008), 19. Available: http://www.jisc.ac.uk/media/documents/programmes/reppres/gg_final_keynote_11012008.pdf

8. Peter Williams, "The Net Generation: The Experiences, Attitudes and Behaviour of Children Using the Internet for their Own Purposes”, Aslib Proceedings, 51, no. 9 (October 1999), 318.

9. UCL CIBER Project, Information Behaviour, 9-10.

10. Wendy Holliday and Qin Li, "Understanding the Millennials: Updating our Knowledge about Students," Reference Services Review, 32, no. 4 (2004), 364.

11. UCL CIBER Project, Information Behaviour, 12.

12. Cathy DeRosa, Joanne Cantrell, Janet Hawk, and Alane Wilson, College students' perceptions of libraries and information resources: A report to the OCLC membership. Dublin, OH: OCLC Online Computer Library Center (2006), 2-9. Available: http://www.oclc.org/reports/pdfs/studentperceptions.pdf.

13. Williams, "The Net Generation," 319. 
14. Jones, The Internet Goes to College, 12.

15. Amanda Lenhart, Lee Rainie, and Oliver Lewis, Teen Life Online: The Rise of the Instantmessage Generation and the Internet's Impact on Friendships and Family Relationships. Washington, DC: Pew Internet and American Life Project (June 21, 2001), 35. Available: http://www.pewinternet.org/ /media//Files/Reports/2001/PIP_Teens_Report.pdf.pdf

16. DeRosa, Cantrell, Hawk, and Wilson, College Students' Perceptions of Libraries, 1-13, 2-9.

17. Online Computer Library Center, OCLC White Paper on the Information Habits of College Students: How Academic Librarians Can Influence Students' Web-based Information Choices (June, 2002), 9.

18. Alison J. Head and Michael B. Eisenberg, "Finding Context: What Today's College Students Say about Conducting Research in the Digital Age," Project Information Literacy Progress Report, Information School, University of Washington (February 4, 2009), 4. Available: http://projectinfolit.org/pdfs/PIL_ProgressReport_2_2009.pdf.

19. Joan Stein, Alice Bright, Carol George, Terry Hurlbert, Erica Linke, and Gloriana St. Clair, "In their Own Words: A Preliminary Report on the Value of the Internet and Library in Graduate Student Research,” Performance Measurement and Metrics, 7, no. 2 (2006), 110.

20. Ibid., 112.

21. Donald A. Norman, "Some Observations on Mental Models," in Mental models , edited by Dedre Genter \& Albert L. Stevens (Hillsdale, NJ: Lawrence Erlbaum, 1983), pp. 7-14.

22. Alexandra Dimitroff, "Mental Models Theory and Search Outcome in a Bibliographic Retrieval System,” Library \& information science research, 14, no. 2 (1992), 141-156.

23. Stephen T. Kerr, "Wayfinding in an Electronic Database: the Relative Importance of Navigational Cues vs. Mental Models," Information Processing \& Management, 26, no. 4 (1990), 511-523.

24. Gary Marchionini, "Making the transition from print to electronic encyclopaedias: Adaptation of mental models," International Journal of Man-Machine Studies, 30, no. 6 (1989), 591- 618.

25. Scharlotte Ann Saxon, Seventh grade students and electronic information retrieval systems: An exploratory study of mental model formation, completeness and change (Doctoral dissertation, Florida State University, 1997).

26. Debra J. Slone, "The Influence of Mental Models and Goals on Search Patterns During Web Interactions," Journal of the American Society for Information Science and Technology, 53, no.3 (2002), 1152-1169. 
27. D. Scott Brandt and Lorna Uden, "Insight into Mental Models of Novice Internet Searchers," Communications of the ACM, 46, no. 7 (2003), 133-136.

28. D. Scott Brandt, "Constructivism: Teaching for Understanding of the Internet. Communications of the ACM, 40, no. 10 (1989), 112 - 117.

29. Xiangmin Zhang and Mark Chignell, "Assessment of the Effects of User Characteristics on Mental Models of Information Retrieval Systems," Journal of the American Society for Information Science and Technology, 52, no. 6 (2001), 445-459.

30 Ibid.

31. Kathleen Guinee, Maya B. Eagleton, and Tracey E. Hall, “Adolescents' Internet Search Strategies: Drawing upon Familiar Cognitive Paradigms when Accessing Electronic Information Sources," Journal of Education Computing Research, 29, no. 3 (2003), 368-369.

32. UCL CIBER Project, Information Behaviour, 20-22.

33. Yan Zhang, "The Influence of Mental Models on Undergraduate Students' Searching Behavior on the Web," Information Processing and Management, 44, no. 3 (2008), 1330-1345.

34. Prensky, Digital Natives, Digital Immigrants, 3-4.

35. Diana G. Oblinger and James L. Oblinger, "Is It Age or IT: First Steps toward Understanding the Net Generation." In D. G. Oblinger and J. L. Oblinger (Eds.), Educating the Net Generation (pp. 2.1- 2.20). Boulder, CO: Educause (2005), 2.14-2.15. Available: http://www.educause.edu/educatingthenetgen/

36. UCL CIBER Project, Information Behaviour, 9-10. 
Millennials' Mental Models 24 |

TABLE 1 Searches conducted in search engines and databases

\begin{tabular}{|c|c|c|c|c|c|c|c|}
\hline $\begin{array}{l}\text { Search } \\
\text { Engine }\end{array}$ & $\begin{array}{l}\text { Number of } \\
\text { Searches }\end{array}$ & $\begin{array}{l}\text { Percent of } \\
\text { engine } \\
\text { searches }\end{array}$ & $\begin{array}{l}\text { Percent of } \\
\text { Total } \\
\text { searches }\end{array}$ & Database & $\begin{array}{l}\text { No. of } \\
\text { Searches }\end{array}$ & $\begin{array}{l}\text { Percent of } \\
\text { Database } \\
\text { searches }\end{array}$ & $\begin{array}{l}\text { Percent of } \\
\text { Total }\end{array}$ \\
\hline Google & 92 & 72.3 & & $\begin{array}{l}8 \text { Acad. Search } \\
\text { Premier }\end{array}$ & 59 & 73.8 & 28.1 \\
\hline Alta Vista & & 5.4 & & 3 JSTOR & 6 & 7.5 & 2.8 \\
\hline Yahoo & & 3.8 & & $\begin{array}{l}4 \text { Opposing } \\
\text { Viewpoints }\end{array}$ & 4 & 5.0 & 1.9 \\
\hline Ask & & 3.8 & & 4 InfoTrac & 4 & 5.0 & 1.9 \\
\hline $\begin{array}{l}\text { Google } \\
\text { Scholar }\end{array}$ & & 3.1 & 1. & 9 LexisNexis & 3 & 3.8 & 1.4 \\
\hline Google Gov & & 2.3 & 1. & 4 Lib. Catalog & 1 & 1.3 & 0.5 \\
\hline $\begin{array}{l}\text { Google } \\
\text { Images }\end{array}$ & & 2.3 & 1. & 4 Journal Finder & 1 & 1.3 & 0.5 \\
\hline PolyCola & & 2.3 & 1. & 4 Project Muse & 1 & 1.3 & 0.5 \\
\hline MSN & & 1.5 & & $\begin{array}{l}9 \text { Gen. Business } \\
\text { File }\end{array}$ & 1 & 1.3 & 0.5 \\
\hline Wikipedia & & 1.5 & 0. & & & & \\
\hline Clusty & & 0.8 & 0. & & & & \\
\hline Encarta & & 0.8 & 0. & & & & \\
\hline$N$ & 130 & 10.00 & 61.9 & & 80 & 100.0 & 38.1 \\
\hline
\end{tabular}


Millennials’ Mental Models 25

TABLE 2 Type of Search

\begin{tabular}{lrr}
\hline Method & Number & Percent of total \\
\hline Simple searches & 77 & 34.4 \\
Topic plus focus searches & 68 & 30.4 \\
Phrase searches & 39 & 17.4 \\
Boolean searches & 31 & 13.8 \\
Use of subject headings & 9 & 4.0 \\
$N$ (includes 210 searches in search engines & 224 & 100.0 \\
and 14 searches within individual sites) & & \\
\hline
\end{tabular}


TABLE 3 Application of advanced techniques and common mistakes

\begin{tabular}{lrr}
\hline Method & Number of Attempts & Percent of total searches (224) \\
\hline Broaden / Narrow & 24 & 10.7 \\
Limits & 2 & 0.9 \\
Truncation & 5 & 2.2 \\
Spelling errors & 18 & 8.0 \\
Boolean mistakes & 21 & 9.3 \\
Unnecessary words & 6 & 2.7 \\
Incorrect punctuation & 4 & 1.8 \\
$N$ & 80 & 35.6 \\
\hline
\end{tabular}




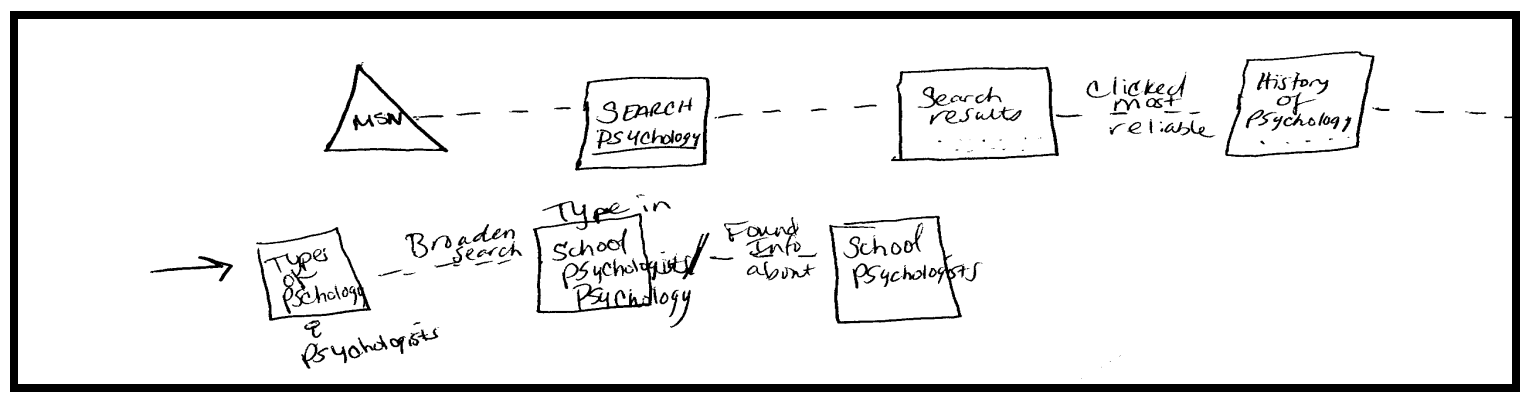

Figure 1. Process view mental model. 


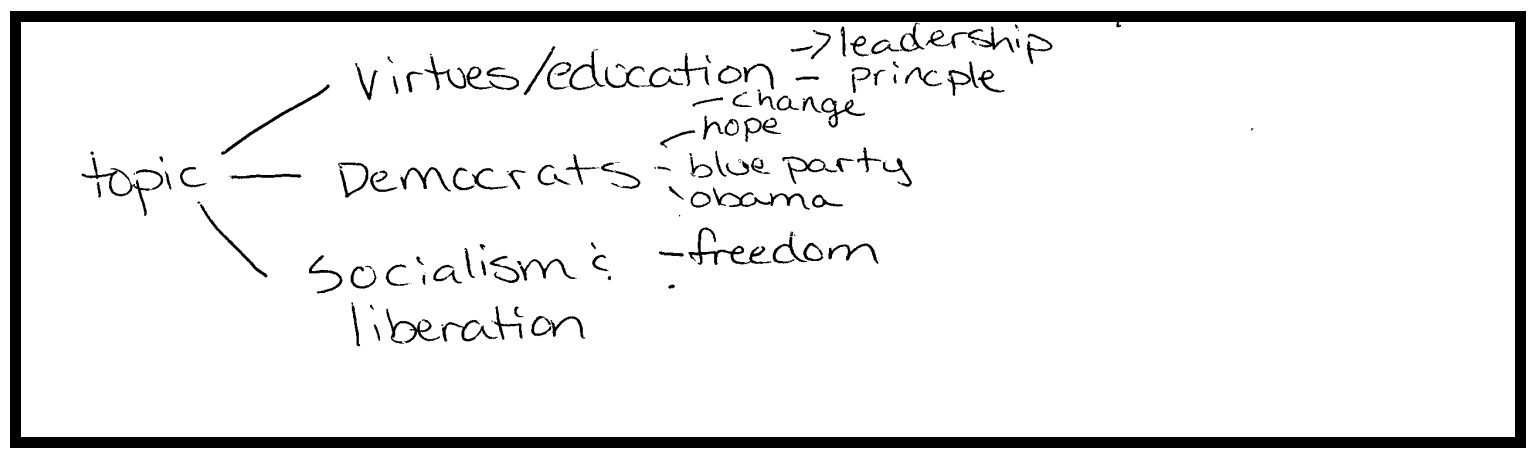

Figure 2. Hierarchical view mental model. 


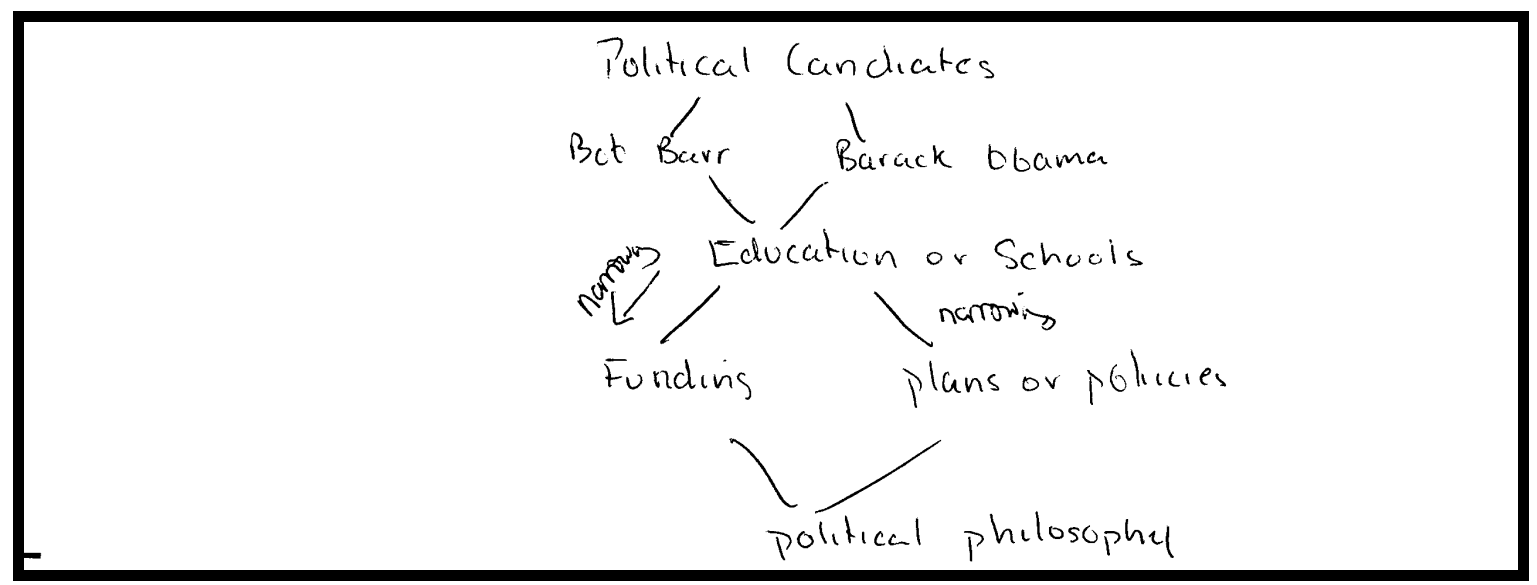

Figure 3. Network view mental model. 
Millennials' Mental Models 30

TABLE 4. Type of search by mental model

\begin{tabular}{lrrrrrrr}
\hline Type of Search & Process & \% & Hierarchy & \% & Network & \% & $\begin{array}{r}\text { Total } \\
(\mathbf{n = 2 0 6})^{*}\end{array}$ \\
\hline Simple & 11 & 15 & 32 & 44 & 30 & 41 & 73 \\
Topic+Focus & 5 & 8 & 10 & 17 & 45 & 75 & 60 \\
Phrase & 8 & 20 & 10 & 24 & 23 & 56 & 31 \\
Boolean & 0 & 0 & 4 & 17 & 20 & 83 & 24 \\
Subject Head. & 0 & 0 & 5 & 63 & 3 & 38 & 8 \\
Total & 24 & 11.6 & 61 & 29.6 & 121 & 58.7 & 206 \\
\hline
\end{tabular}


Millennials’ Mental Models 31

TABLE 5. Number of searches by mental model.

\begin{tabular}{lrrrrrrrrrr}
\hline $\begin{array}{l}\text { Mental } \\
\text { Model }\end{array}$ & Simple & $\%$ & $\begin{array}{r}\text { Topic }+ \\
\text { Focus }\end{array}$ & \% & Phrase & $\%$ & Boolean & \% & $\begin{array}{r}\text { Subject } \\
\text { Headings }\end{array}$ & \% \\
\hline Process & 11 & 46 & 5 & 21 & 8 & 33 & 0 & 0 & 0 & 0 \\
Hierarchy & 32 & 52 & 10 & 16 & 10 & 16 & 4 & 7 & 5 & 8 \\
Network & 30 & 25 & 45 & 37 & 23 & 19 & 20 & 17 & 3 & 2
\end{tabular}

